\title{
Study on the Innovation of Students' Practical Link in College English Teaching based on Liberal Education
}

\author{
Ying Chen \\ School of Foreign Studies, Xi'an University, Xi'an Shaanxi, 710065
}

Keywords: Liberal Education; University; English Teaching; Practice; Innovation

\begin{abstract}
As a universal language of communication, the importance of English is self-evident. English education and teaching in colleges and universities of our country started earlier. After these years of continuous development, it has made considerable achievements in many aspects. However, there are some drawbacks in English teaching and learning in Chinese colleges and universities. With the promotion of liberal education, some of the drawbacks in college English teaching have even become the bottleneck of the healthy development of college English teaching and learning. The lack of attention to the students' practice is one of the outstanding problems in the teaching process. This paper makes a brief research on the innovative methods of students' practice in college English teaching based on the background of liberal education.
\end{abstract}

English education and teaching in China's colleges and universities started early,and has formed a relatively perfect system.After years of continuous exploration and development,English teaching in colleges and universities of our country has made remarkable achievements in some aspects. While we see the results,we can't ignore the problems.Some of these problems are universal,while others are specific. For example,students' practical ability is not strong,and this problem is a common problem in higher education in our country.Although some changes have been made in recent years, the changes are more concentrated in science and Engineering and arts majors.This problem is still very prominent.

\section{Analysis of the reasons for the weakness of students' practice in college English Teaching}

The problem of attaching importance to theory but ignoring practice has been puzzling the healthy development of higher education in China for a long time.There are profound historical and objective reasons for the existence of this issue.As far as I am concerned,the main factors contributing to this situation are:

\subsection{Discrepancies in understanding}

For a long time,we seem to have a special preference for theoretical knowledge.Since the introduction of English teaching in colleges and universities,we have attached great importance to the students' study of English theoretical knowledge. Whether in the curriculum design,or in the textbook configuration,you can see the traces of this idea.Even today,many teachers and parents still 
have a very one-sided understanding of English.They consider the English grammar and basic knowledge of English to form the most basic elements of the English knowledge system.To learn English well,students must learn English theoretical knowledge.This view is very wrong to understand from the whole.The reason why we say that it is wrong is not that the theoretical knowledge of English is not important.On the contrary,we think that English theoretical knowledge is an important part of English knowledge.But English knowledge and English ability constitute a scientific whole,rather than simply a patchwork of factors. While we attach importance to the learning of English theoretical knowledge,we can not neglect the cultivation of students' practical ability.The communicative nature of English itself determines that English is a highly practical course,and the study of theoretical knowledge alone is not enough to support the integrity of the whole English system.At the same time,we must also see,the English practice link regarding the student grasps the English theory knowledge to have the huge promoter action.The two should complement each other,and promote each other,only because of our understanding of the deviation led to the separation of the two.

\subsection{The deficiency of teachers 'ability and quality}

The teacher is engaged in the education teaching the most key factor,and is also the education teaching development front.Under the current college system,most of our college English teachers are English majors,and few of them have participated in English practice in their own learning process.At the same time,Since education and professional learning are not the same thing in themselves,many college English teachers have such a confusion in education and teaching that they have very strong English professional knowledge,but they always feel full of butterflies in education and teaching.I can't fly,there is a sense that talent can not be developed.The main reason for this phenomenon is that normal universities mainly train students' teaching ability,and English universities mainly let students learn professional knowledge.It is the reason of this kind of system that causes the English teachers in colleges and universities in our country to be generally lack of ability to organize students to carry out practical work.In recent years,due to the reasons of knowledge or funds,there is not enough effort in the two aspects of teacher retraining and re-study.Many teachers have not significantly improved their ability and quality since they set foot on the job.Cultivating students' practical ability and strengthening the practical link of college English learning have very strong requirements for curriculum design,curriculum organization ability,etc.Regrettably,There is a big gap between the comprehensive competence of our college English teachers and the requirements of this work.

\subsection{Lack of practical measures}

How to improve the English practice ability of college students,the simplest and most effective way to improve college students' English practice ability is to let them participate in social practice extensively.Social practice is a broad concept.In some ways,any social activity that can let students participate in and exercise their English language ability can be called social practice.But there is a question of good results.How to improve students' English application ability and practice efficiency is not only an educational problem,but also a social problem. The solution of this problem needs the common concern and joint efforts of the whole society.Generally speaking,the practical measures and approaches of college students' English learning are very limited.In recent years,the issue has been gradually attached importance to by all sectors of society. 


\subsection{The practical teaching method is out of date}

In recent years,although the practical teaching ability of colleges and universities in our country has been improved in some aspects,on the whole,the teaching method still seems rather old-fashioned.At present,English teaching in colleges and universities has undergone a series of reforms in teaching content,course system construction and practice course setting,but the teaching mode of practice course is still quite single practice curriculum management is also more rigid.These have seriously affected the student's study enthusiasm and the initiative.The teacher-centered practical education mode still occupies a dominant position,and the students are basically in the range set by the teacher, and the practice link is mechanical.

\subsection{Lack of proper humanistic education}

In the social environment,colleges and universities cannot exist independently from the social environment.Under the current market economy conditions,various concepts are washed away and multiple cultures collide.Pragmatism,consumerism is popular.These cultural phenomena will inevitably affect the school and the majority of students,among which the negative factors have a greater impact on the majority of teachers and students,even to a certain extent about the value orientation of teachers and students.Humanism not only affects students' theoretical learning,but also students' practical ability.Due to the deviation of understanding,many students have very limited cultural views,and their ability to distinguish is not strong.They are vulnerable to external disadvantages in social practice.

\section{The interaction between practical ability and English learning in the context of liberal education}

What's a liberal education?What kind of educational and teaching effect does the liberal education want to achieve?These are the first two things we need to know about liberal education.At present,China is in a period of rapid economic and social development,and the demand for high-quality English talents has shown explosive growth.At the same time,our country each year raises the English talented person number is also a huge figure.However,there is a huge gap between the demand for talents and the output of talents.On the one hand,many enterprises and units are eager for talents,but they can not recruit suitable talents. On the other hand,a large number of graduates can not find suitable jobs. What is the reason for this seeming contradiction?The reason is that our talent cultivation ability and talent cultivation goal can not match with the needs of the society.Some educators have been concerned with this issue for a long time,and some scholars think that if we let it go,eventually our educational system will be totally obsolete.It is against this background that the liberal education education reform is launched and pushed forward.The core of liberal education is to emphasize students' self-learning ability and ability to apply knowledge.There is a close relationship between strengthening practice and cultivating students' ability of self-study and knowledge application.

Therefore,in the background of advocating liberal education,we advocate to highlight and strengthen the practical link in students' learning,which is not only the need of educational reform and development,but also the measure of adapting to the development of the Times.Students can deepen the understanding of knowledge,and strengthen the ability to use knowledge through practice.In turn,the problems encountered in practice will urge them to take the initiative to learn.It's a virtuous cycle.Theory itself comes from practice,and any thought or practice that separates theory from practice is wrong. 


\section{The liberal education of college English teaching practice students innovative methods}

In order to carry out the innovation of students' practice in college English teaching under the background of Liberal Education,we should renew the practice mode,strengthen the academic exchange,and combine school with enterprise to run a school.

\subsection{Updating practice way}

With the development of technology,especially computer technology and information technology for education and teaching reform provides a very broad platform. At present,the practice teaching platform based on internet + has been widely used in many schools. The practical teaching platform based on internet + is based on Internet technology and new media technology..This platform makes full use of the Internet and new media technology advantages,breaking the traditional practice of time and space for the dependence.The practice system based on this technology can allow students to fully participate in the practice of the use of English without leaving home.At present,several 211 universities in Beijing have established a complete English practice teaching system based on internet + .One end of the system is connected to the school,and the other end can be switched to a foreign academic system in real time.Students can play different roles in the system through the terminal and fully communicate with other users in the system.

\subsection{Strengthening academic exchanges}

How to improve students' foreign language practice learning ability,this issue is not only our concern,foreign counterparts are also conducting corresponding research.According to the current research results in foreign countries,the most effective way to improve students' language competence is to communicate with students of different languages.Countries such as the United States and the United Kingdom have applied this research to their teaching practice.They encourage and promote the introduction of foreign students into their foreign language teaching classes,allowing students from different languages and cultures to communicate and learn together.Achieving the goal of improving students' comprehensive language ability through the subtle influence between students and students.In Asian countries,Japanese universities are at the forefront of this field.One of their higher education funds is devoted to bringing foreign students to foreign language classes in their home country.It is of great significance to strengthen the academic exchange activities between students of different cultures and languages for improving students' language practice ability,training students' self-confidence and enriching their foreign cultural accomplishment.

\subsection{Joint Operation}

The mode of school-enterprise joint running was first applied in the teaching practice of science and engineering,and then gradually expanded to the field of liberal arts.If the school-enterprise union is well organized and planned scientifically,it can not only play an important role in alleviating the shortage of students,but also enhance the students' learning and practice.First of all,we must make it clear with which enterprises and employing units to jointly run schools.As far as English majors are concerned,such as publishing houses,tourism companies,foreign-related units are more ideal targets.Students can find their own shortcomings in the practice process,timely adjustment of learning methods and learning direction through the school-enterprise joint school. 


\section{Conclusion.}

English is a course system based on practice. Practice plays an indispensable role in English learning. How to let the students use in learning, in using middle school, to achieve the use of learning, to use to promote learning in college English teaching is an important issue that we need to solve. As a college English educator, how to grasp the opportunity of curriculum reform and promote the sustainable and healthy development of college English practice teaching is a historical topic.

\section{References}

[1] Xu Yanqiu.Humanities Education in College English Teaching [J]. Journal of Northeastern University. 2002(03)

[2] Zhang Yanxian.How to Infiltrate the Concept of "Cooperative Interaction" in New Target English Teaching [J]. Times Education. 2010(03)

[3] Xie Xuehua. Exploring the Relationship between Basic English Teaching and Special Purpose English Teaching [J]. Journal of Shandong Education Institute. 2005(04)

[4] Zhao Hong. Research Teaching and Reform of University Teaching Methods [J]. Higher Education Research, 2006, (02)

[5] Ding Jie. Exploration on the Ways of Engineering Education Innovation Training Mode in Colleges and Universities [J]. Economic Research Guide, 2011

[6] Zhang Xiaotang. The Present Situation and Reform Countermeasures of College Training (Inspection)[J].Journal of Chifeng College,2009,(8) 